\title{
Deciphering fact from artifact when using reporter assays to investigate the roles of host factors on L1 retrotransposition
}

\author{
Pamela R. Cook ${ }^{1 *}$ (D) and G. Travis Tabor ${ }^{2}$
}

\begin{abstract}
Background: The Long INterspersed Element-1 (L1, LINE-1) is the only autonomous mobile DNA element in humans and has generated as much as half of the genome. Due to increasing clinical interest in the roles of L1 in cancer, embryogenesis and neuronal development, it has become a priority to understand L1-host interactions and identify host factors required for its activity. Apropos to this, we recently reported that L1 retrotransposition in HeLa cells requires phosphorylation of the L1 protein ORF1p at motifs targeted by host cell proline-directed protein kinases (PDPKs), which include the family of mitogen-activated protein kinases (MAPKs). Using two engineered L1 reporter assays, we continued our investigation into the roles of MAPKs in L1 activity.

Results: We found that the MAPK p38 8 phosphorylated ORF1p on three of its four PDPK motifs required for L1 activity. In addition, we found that a constitutively active p38 $\delta$ mutant appeared to promote $L 1$ retrotransposition in HeLa cells. However, despite the consistency of these findings with our earlier work, we identified some technical concerns regarding the experimental methodology. Specifically, we found that exogenous expression of p38 $\delta$ appeared to affect at least one heterologous promoter in an engineered L1 reporter, as well as generate opposing effects on two different reporters. We also show that two commercially available non-targeting control (NTC) siRNAs elicit drastically different effects on the apparent retrotransposition reported by both L1 assays, which raises concerns about the use of NTCs as normalizing controls.

Conclusions: Engineered L1 reporter assays have been invaluable for determining the functions and critical residues of $L 1$ open reading frames, as well as elucidating many aspects of $L 1$ replication. However, our results suggest that caution is required when interpreting data obtained from L1 reporters used in conjunction with exogenous gene expression or siRNA.
\end{abstract}

Keywords: L1, LINE-1, Reporter, Host factor, p38, HSV-TK, SV40, Promoter, Renilla

\section{Background}

The only active, autonomous mobile DNA element in humans is the Long INterspersed Element-1 (LINE-1, L1) retrotransposon, which is responsible for generating almost half of the human genome via insertion of its own DNA and that of non-autonomous Short-INterspersed repeat Elements (SINES) [1]. These insertions, combined with 3 ' transductions, nonallelic homologous recombination and mobilization of cellular mRNAs, have had a

\footnotetext{
* Correspondence: pamela.cook@nih.gov

'Laboratory of Cell and Molecular Biology, National Institute of Diabetes and Digestive and Kidney Diseases, National Institutes of Health, 8 Center Drive, Bethesda, MD 20892, USA

Full list of author information is available at the end of the article
}

defining impact on genomic architecture, and the consequences on gene regulation and human development are largely unknown [2-5]. L1 activity is restricted to certain cell types (reviewed in [6]), and retrotransposition is thought to occur mainly in embryonic cells [7, 8], pluripotent stem cells $[9,10]$, adult neuronal development [11-15], and cancer [16-19]. Clinical interest in L1 has increased due to its mutagenic and diseasecausing potential $[11,20-23]$, as well as its association with cancer [16-19]. In addition, a growing number of studies suggest that transposable elements can be co-opted to serve fundamental physiological functions [24-30]. Recent work has thus been aimed at identifying cellular host factors required for L1 
expression, repression and reactivation. With respect to this, our laboratory recently demonstrated that host proline-directed protein kinase (s) (PDPKs) phosphorylate the L1 protein ORF1p on multiple PDPK motifs required for L1 retrotransposition [31].

PDPK target motifs consist of serines or threonines with a proline in the +1 position (S/T-P motifs), which in ORF1p are: S18/P19; S27/P28; T203/P204; and T213/ P214. The PDPK family includes mitogen-activated protein kinases (MAPKs), cyclin dependent kinases (CDKs) and glycogen synthase kinase 3 (GSK3). Prior to our finding that the phosphorylation of ORF1p by PDPKs is necessary for $\mathrm{L} 1$ activity, several studies reported associations between L1 and the PDPK p38 [32-34], a MAPK that exists in four different isoforms, $\alpha, \beta, \gamma$ and $\delta$ [35]. Moreover, the expression of one isoform, p38 $\delta$, can be induced in primary cell cultures via exogenous expression of ORF1p [34].

Given these associations between L1 and the PDPK p38, as well as our previous findings that host PDPKs are required for $\mathrm{L} 1$ retrotransposition, we decided to investigate the role of each p38 isoform on ORF1p phosphorylation and L1 activity. Although our studies are ongoing, we believe that dissemination of our present findings and their associated experimental pitfalls will be useful to the L1 research community. We report here that: 1) different populations of HeLa cells can result in different experimental outcomes; 2) two presumably complementary L1 retrotransposition reporter assays produced conflicting results when coupled with exogenously expressed p388; and 3) two different non-targeting control (NTC) small interfering RNA (siRNA) sequences differentially affected measured L1 activity.

\section{Results}

\section{MAPK p38ס phosphorylates ORF1p on S/T-P motifs}

We first determined whether activated wild type $\mathrm{p} 38 \delta$ (WT, Invitrogen) could phosphorylate ORF1p on its S/ T-P motifs, which are required for robust L1 activity [31]. In vitro radioactive kinase assays revealed that p38ס-WT exclusively phosphorylated bacterially purified ORF1p on these residues, as an ORF1p carrying mutations at all four motifs, S18A/S27A/T203G/T213G (AAGG), was not phosphorylated (Fig. 1a top). We next tested the ability of $\mathrm{p} 38 \delta$-WT to phosphorylate the ORF1p mutants S18A/S27A (AA) and T203G/T213G (GG), and found that the majority of phosphorylation occurred on the GG mutant, which retained both serine motifs (Fig. 1a top).

In order to compare the degree of phosphorylation at each motif, we constructed a series of mutants, each bearing only one intact S/T-P motif: SAGG (S27A/ T203G/T213G); ASGG (S18A/T203G/T213G); AATG (S18A/S27A/T213G); and AAGT (S18A/S27A/T203G).

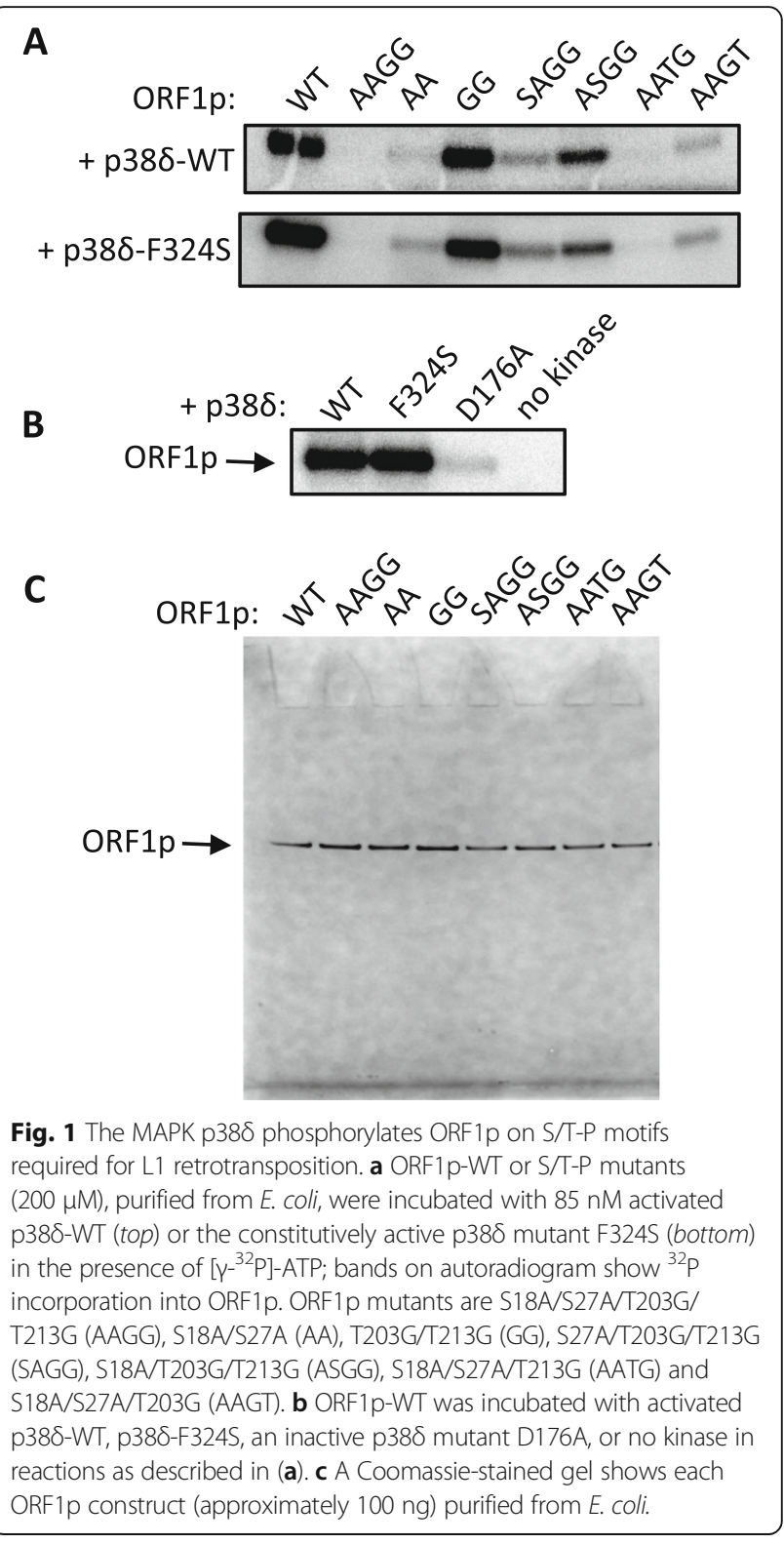

S27 (ASGG) was phosphorylated by p38 $\delta$-WT to the greatest extent (Fig. 1a top). T213 (AAGT) was phosphorylated to approximately the same degree as S18 (SAGG), but p38ס-WT showed almost no activity on T203 (AATG). Of note, results from the kinase prediction program NetPhosK 1.0 [36] indicated that unspecified p38 isoforms were expected to target ORF1p at S18, T203 and T213, but not S27.

\section{Constitutively active $\mathrm{p} 38 \delta-\mathrm{F} 324 \mathrm{~S}$ retains ORF1p substrate specificity}

Various p38 $\delta$ mutants that retain some degree of constitutive activity independent of phosphorylation by their activating upstream kinases in the MAPK pathway have been described [37]. In those studies, the constitutively 
active mutant $\mathrm{p} 38 \delta$-F324S retained the substrate specificity of activated $\mathrm{p} 38 \delta$-WT for glutathione S-transferase activating transcription factor 2 (GST-ATF2) in vitro when $\mathrm{p} 38 \delta$-F324S was purified from bacteria or immunoprecipitated from HEK293 cell lysates. We found that bacterially purified $\mathrm{p} 38 \delta$-F324S also exhibited wild type substrate specificity for ORF1p's S/T-P motifs (Fig. 1a bottom). In addition, we tested the mutant $\mathrm{p} 38 \delta$-D $176 \mathrm{~A}$, which was reported to have no activity on GST-ATF2 when purified from bacteria but greater activity than p38 $\delta$-WT when immunoprecipitated from HEK293 cells [37]. Bacterially purified p388-D176A barely phosphory-

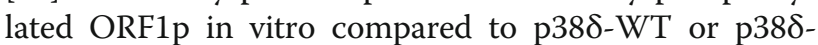
F324S (Fig. 1b). Figure 1c shows each ORF1p construct, purified from E. coli, used for the in vitro kinase assays.

\section{L1 reporter assays}

Given our findings that $\mathrm{p} 38 \delta$ specifically phosphorylated ORF1p S/T-P motifs, we proceeded to determine the effect of $\mathrm{p} 38 \delta$ on L1 retrotransposition. To assess this, we used two previously characterized L1 reporter assays. The original L1 retrotransposition reporter, JM101 (a kind gift from Dr. John Moran), relies on the splicing of an artificial intron from an L1-borne neomycin-resistant gene and its L1-mediated conversion into genomic DNA to produce cell foci resistant to the neomycin analog G418 [38]. Specifically, the reporter contains a fulllength L1 element driven by the cytomegalovirus (CMV) promoter and an mneo cassette that encodes the neomycin-resistant gene (neo), driven by a Simian virus 40 (SV40) promoter located within the 3 ' untranslated region (UTR) of L1 (Fig. 2 top). The neo gene product, also known as aminoglycoside $3^{\prime}$-phosphotransferase-II (APH (3')-II), phosphorylates and thereby inactivates G418. Selection with G418 is begun approximately three days following transfection of the reporter plasmid into retrotransposition-competent cells and is continued for 10-12 days. The arrangement of the neo gene in JM101 ensures that only cells that have undergone retrotransposition by the L1 reporter element will express APH (3')-II. The coding sequence for neo and its promoter are located on the antisense strand in the 3' untranslated region of L1. Within this sequence is the engineered artificial intron, but it can only be spliced from the L1 sense RNA driven by the L1 promoter due to the orientation of the splice donor (SD) and splice acceptor (SA) sequences. Once spliced, the L1 RNA is retrotransposed into cDNA and inserted into the genome. After synthesis of the complementary DNA strand, which contains the spliced neo template, the transcript for APH (3')-II can be initiated from the antisense promoter.

The more recently developed single-vector dual luciferase L1 reporters (kind gifts from Dr. Wenfeng An) are based on the same principle as the mneo reporter, but instead of neo they contain the gene for Firefly luciferase (Fluc). Fluc is also driven by an SV40 promoter and interrupted by an intron to monitor retrotransposition (Fig. 2, lower schematics) [39]. In addition, this reporter contains an internal control gene expressing Renilla luciferase (Rluc) driven by a Herpes simplex virus thymidine kinase (HSVTK) promoter. Constitutively active Rluc expression is intended as a normalizing control for variations in cell plating, transfection efficiency and survival. Four days following transfection, cells are lysed and retrotransposition is reported as a function of Rluc-normalized Fluc luminescence. The three single-vector luciferase reporters used in this study were: pYX017, which contains an L1 element driven by a hybrid CAG promoter consisting of the CMV enhancer fused with a modified chicken beta-actin promoter and a splice element from the rabbit beta-globin gene [40]; PYX014, which contains only the native L1 promoter in the 5'UTR; and pYX015, a negative control, which is identical to pYX014 except that it carries two missense mutations in ORF1p and is thus retrotranspositionincompetent [38, 39].

\section{Constitutively active p38 increases G418-resistant colonies}

Consistent with our in vitro results and our previous findings that the phosphorylation of ORF1p S/T-P motifs is required for robust L1 activity, we found that exogenous expression of the constitutively active p38 $\delta$ F324S (FS) appeared to increase L1 retrotransposition in the G418-based assay relative to an empty vector control (EV), while p38 -D176A (DA), which failed to appreciably phosphorylate ORF1p in vitro, inhibited L1 (Fig. 3a top). Surprisingly, p38 8 -WT (WT) also repressed formation of G418-resistant colonies (Fig. 3a top left). These effects did not appear to be a result of altered cell viability, as only p38 8 -D $176 \mathrm{~A}$ somewhat affected cell growth (Fig. 3a bottom left). To determine whether the observed decrease in colony density resulting from $\mathrm{p} 38 \delta$-WT overexpression might be due to effects of the expression vector on cotransfection efficiencies, we cotransfected an expression plasmid for the enhanced green fluorescent protein (EGFP, a kind gift from Dr. Birong Shen) with either the pcDNA empty vector, p38 $\delta$-WT or p $38 \delta$ F324S. Neither p38 $\delta$-WT nor p38 $\delta$-F324S appreciably altered EGFP fluorescence compared to the empty vector (Fig. 3a right).

The inhibition of L1 by p38 $\delta$-WT may be explained by the fact that p38, like other MAPKs, relies on a complex network of docking interactions with many proteins, including substrates, upstream activating MAPK kinases, phosphatases and scaffolding and regulatory factors. These interactions collectively synchronize the activation and localization of p38 via feedback loops and crosstalk with other pathways [[41] and references therein]. Thus, 


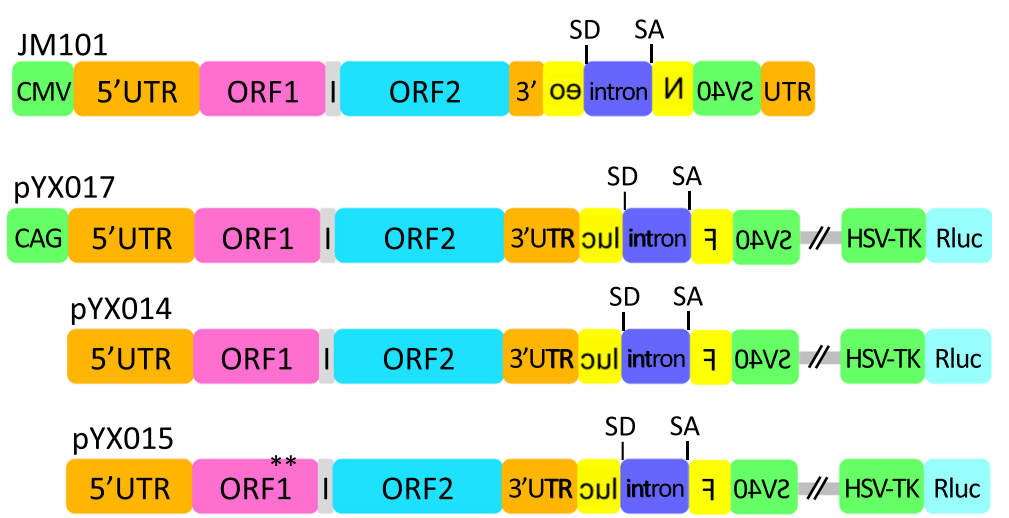

Fig. 2 Schematic of L1 reporter plasmids. All reporters contain a full-length L1 element with 5' and $3^{\prime}$ UTRs (orange), ORF1 (pink), intergenic region (gray), ORF2 (blue) and a retrotransposition reporter (yellow) interrupted by an artificial intron (purple) with splice donor (SD) and acceptor (SA) sites. In JM101, L1 is driven by the CMV promoter (green), and in PYX017 by the hybrid CAG promoter (green). pYX014 contains only the native L1 promoter in the 5'UTR, and pYX015 is identical to pYX014 except for two missense mutations (R261A/R262A) [38] in ORF1p, rendering pYX015 incompetent for retrotransposition. The reporter in JM101 is an mneo cassette driven by the SV40 promoter (green) located within the 3' UTR. The pYX017, pYX014 and pYX015 constructs contain a Firefly luciferase reporter (Fluc), also driven by SV40 (green), as well as a gene for Renilla luciferase (Rluc; aqua) driven by the HSV-TK promoter (green)

a pool of excess, unactivated p38 $\mathrm{k}-\mathrm{WT}$ could perturb this regulatory system, or may simply compete with the population of endogenous activated p38, resulting in inhibition of L1. Consistent with this possibility are several studies that showed expression of a nonfunctional p38 has a dominant negative effect on endogenous p38 activity [42-46]. In addition, during some of our own preliminary experiments, we found on rare occasion that exogenous p38 $\delta$-WT slightly increased rather than decreased the number of G418-resistant colonies (unpublished data), further suggesting that the effect of exogenous p $38 \delta$-WT could depend on cellular conditions that affect the p38 pathway. For example, confluent stock cultures, as opposed to proliferating cultures, have been found to activate endogenous p38 $\alpha$, with effects lasting up to $48 \mathrm{~h}$ after re-plating [47]. However, our investigation of this and several other routine tissue culture variables, including the amount of time cells were exposed to trypsin during sub-culturing, the presence or absence of antibiotics in culture media, lot-to-lot variations in fetal bovine serum (FBS), passage number or overall time in culture, revealed no correlation with the effect of exogenous $\mathrm{p} 38 \delta$ on L1 activity (unpublished data). A previous report indicated that individual HeLa clones can exhibit varying degrees of retrotransposition activity and that certain clones may grow to dominate a mixed culture over time [48]. This phenomenon may also bear on how exogenous host factors impact L1 activity.

\section{Effects of MAPK p388-WT differ depending on the L1 re- porter assay used}

As part of our efforts to understand the effects of p38 $\delta$ WT on L1, we used the single-vector dual luciferase assay in parallel with the G418-based assay (i.e. cells were plated from a common suspension and transfected simultaneously using the same reagents). Data from dual luciferase assays are typically normalized to Rluc expression and reported as a ratio of Fluc/Rluc luminescence. Using this method in an experiment done in parallel with the G418-based assay in Fig. 3a, we found that p38 $\mathrm{-WT}$, p38 8 -F324S, and, surprisingly, p38 $\delta$-D176A, increased L1 retrotransposition by $5,7.7$ and 7 fold, respectively (Fig. 3b). However, the Fluc/Rluc luminescence ratio is valid only if the expression of Rluc is independent of the experimental treatment. It is obvious from the individual luminescence data for Fluc and Rluc shown in Figs. 3c and $\mathrm{d}$ that $\mathrm{p} 38 \delta$ expression dramatically affected Rluc luminescence. Such a decrease in Rluc in the absence of a corresponding decrease in cell survival or transfection efficiency would thus artificially inflate the Fluc/Rluc ratio. As shown previously, cell growth was not detectably affected by $\mathrm{p} 38 \delta$-WT or p $38 \delta$-F324S, and we detected no differences in cell densities in any wells during the course of the luciferase assay. Moreover, we found no effect from $\mathrm{p} 38 \delta$-WT or $\mathrm{p} 38 \delta$-F324S in the previous cotransfection efficiency control experiment using EGFP. Combined, these data strongly suggest that Rluc, driven by the HSVTK promoter, is an inadequate normalizing control for these experiments.

Rluc expression notwithstanding, Fluc, like APH (3')II, reports on raw retrotransposition events and would thus be expected to produce results paralleling those of the G418 assay under similar experimental conditions. If we then consider only Fluc luminescence, the effects of p38 8 -F324S and p38 -D176 roughly coincide in direction if not degree with those observed in the G418 assay. However, p38 $\delta$-WT appears to affect the two reporters differently, inhibiting G418-resistant colony formation but slightly increasing Fluc luminescence (Figs. 3a, c and 

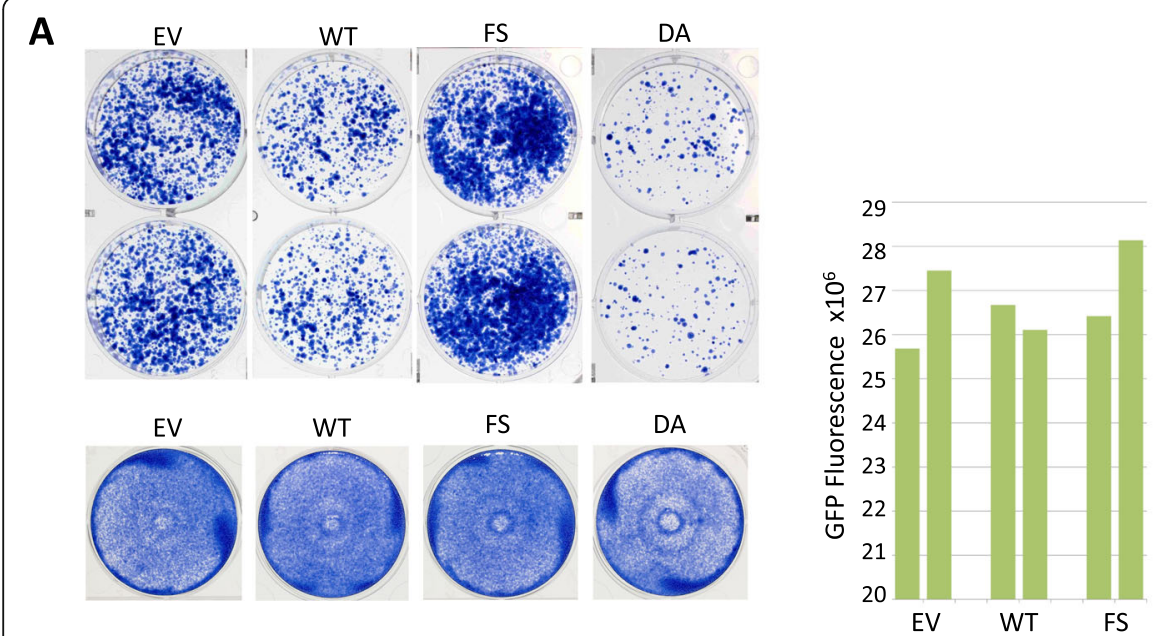

B
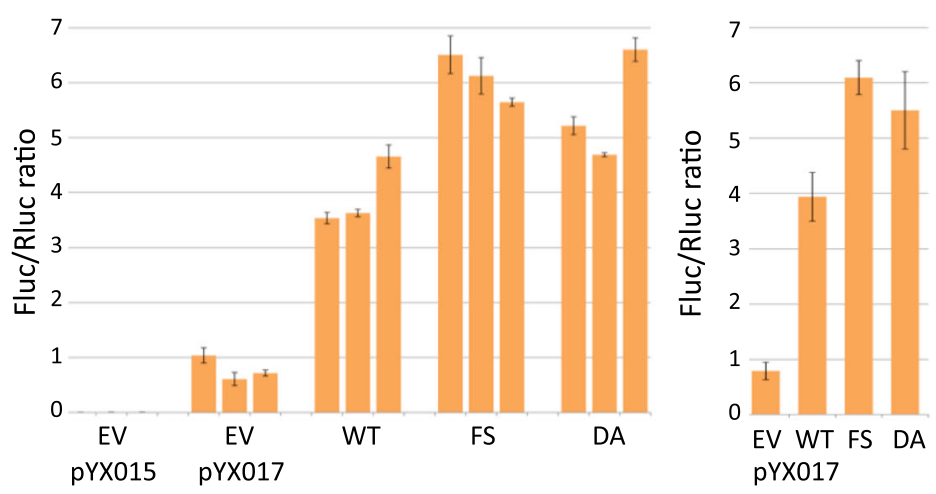

C
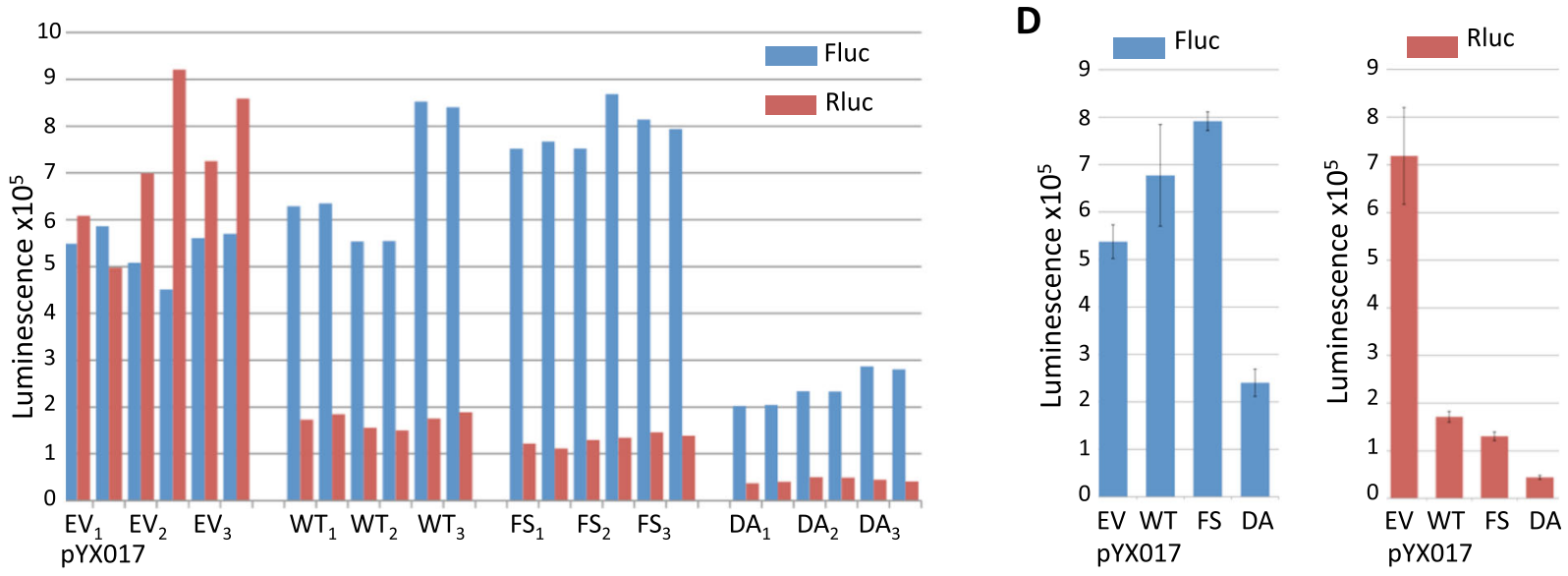

Fig. 3 Effects of p38 on two different L1 reporter assays. a Top rows show duplicate wells of Giemsa-stained G418-resistant colonies resulting from transfection of the L1 reporter JM101 in the presence of pcDNA mammalian expression vectors for: empty vector (EV), p388-WT (WT), p38ס-F324S (FS) or p388-D176A (DA). Bottom row shows the effect of each pcDNA expression vector on cell growth. The right panel indicates fluorescence intensities obtained from cotransfection of EGFP with each indicated p38 construct or empty vector; results from duplicate wells are shown. b Relative Fluc/Rluc luminescence ratios obtained from lysates of HeLa cells transfected with the L1 reporter plasmid pYX015 or pYX017 in the presence of indicated pcDNA mammalian expression vectors. Three biological replicates are shown for each experimental condition; error bars represent the SEM from two technical replicates (defined as two distinct samples taken from each biological sample). The graph at right shows the average of three biological replicates shown separately in the left panel; error bars indicate the SEM, $n=3$ biological replicates. $\mathbf{c}$ Individual luminescence values are shown for Fluc (blue) and Rluc (red) used to calculate the Fluc/Rluc ratios from pYX017 in (b); technical replicates are side-by-side; biological replicates are indicated in subscript. $\mathbf{d}$ Mean Fluc and Rluc luminescence values were derived by first averaging the technical replicates for each biological sample $(n=2)$, and then averaging the resulting values of each biological replicate; error bars represent the SEM of biological replicates, $n=3$ 
d left). As with the G418 assay, our preliminary experiments using the dual luciferase assay sometimes showed an outlier effect of p38 $\delta$-WT, but in this case the outlier was repression of Fluc (unpublished data). Although sub clonal HeLa populations may have been a contributing factor in those experiments, which utilized different stocks of cells, it would not explain differential effects of p38 3 -WT on two reporters in experiments performed in parallel using a common suspension of HeLa cells.

Two questions thus arose: 1) why did $\mathrm{p} 38 \delta$-WT predominantly decrease colony numbers in the G418 assay but increase Fluc luminescence, while the effects of p38 -F324S and p388-D176A remained consistent between the two reporters, and 2) what is the cause of decreased Rluc expression in the presence of $\mathrm{p} 38 \delta$ ?

With respect to the first question, it may be significant that variations were most evident in response to $\mathrm{p} 38 \delta$-WT since it, unlike F324S, would be dependent on a network of cellular factors for activation. This possibility notwithstanding, if the inhibitory effects of p38 $\delta$-WT in the G418-based assay arose from competition with endogenous $\mathrm{p} 38 \delta$, one would expect equivalent competition, not activation, with the pYX017 reporter. Since this was not what we observed, we then considered variables in the assays themselves that might explain the differential effects of p38 $\delta$-WT.

The first and most obvious difference between the two reporters is that $\mathrm{L} 1$ is driven by a CMV promoter in JM101 but a CAG promoter in pYX017, though the CAG promoter contains a CMV enhancer element (Fig. 2). CMV promoters can be affected by some p38 isoforms [49-53], but we did not observe a significant effect of p38 $\delta$-WT or p38 $\delta$-F324S on EGFP, which is also driven by a CMV promoter. To address whether the increase in Fluc luminescence stemmed from effects of p38 $\delta$ on the CAG promoter, we used the pYX014 construct, which is identical to pYX017 except that it relies on the native L1 promoter in the 5' UTR for L1 expression instead of CAG (Fig. 2). Using JM101 in parallel with pYX014, we again found that p38 $\delta$-WT inhibited formation of G418-resistant colonies (Fig. 4a), while both $\mathrm{p} 38 \delta$-WT and p388-F324S increased Fluc luminescence from pYX014 by 1.5 and 2.2 fold, respectively (Figs. 4b left and c), compared to 1.3 and 1.5 fold from pYX017 (Fig. 3d left). Since p38 $\delta$-WT increased Fluc in both pYX014 and pYX017, the effect of p38 $\delta$-WT appears to be independent of the CAG promoter in pYX017. We eliminated p38 8 -D176A from this and further experiments given its effect on cell growth (Fig. 3) as well as the report that, despite its inactivity in vitro, it can be activated in HEK293 cells [37], making its effects on L1 uninterpretable, particularly given the inhibitory effect of p38 $\delta$-WT on G418-resistant colony formation.

Regarding the effect of $\mathrm{p} 38 \delta$ on Rluc luminescence, we considered three possible explanations: 1 ) cell death; 2) transcription or translation interference from pcDNAp388; or 3) inhibition of the Rluc HSV-TK promoter.

As stated earlier, we found no evidence of cell death, despite a 76-94\% decrease in Rluc luminescence using pYX017 (Figs. 3c and d right) and similar decreases with pYX014 (Fig. 4b right and c). Moreover, the decrease in Rluc luminescence from the retrotransposition defective pYX015 (Fig. 4c) ruled out the possibility that rampant L1 activity severely compromised the cells, an event the G418-based assay could have potentially missed.

The second option was that decreased Rluc luminescence resulted from generalized transcription and/or translation interference from the cotransfected plasmids. Competition for cellular factors can be relevant at multiple points, including promoter binding, transcription initiation, elongation or translation [54-57]. For example, the different levels of Rluc luminescence from pYX017 (Fig. 3) compared with pYX014 (Fig. 4) might suggest that the highly active heterologous CAG promoter in pYX017 competed with factors required by the HSV-TK promoter driving Rluc in pYX017. Also, the empty vector control lacked an optimized Kozak sequence, which may have rendered it less effective at competing for translational machinery than the $\mathrm{p} 38 \delta$ constructs. To determine if the kinase-containing plasmids competed with pYX017 for factors necessary for Rluc expression, we cotransfected the L1 reporter with plasmids encoding constitutively active MAPK-kinases (MAPKKs) MKK3b-S288E/T222E (M3) or MKK6-S207E/T211E (M6), which are specific upstream activators of p38 isoforms [58-60]. Unlike p388, each MKK upregulated Rluc (Fig. 5a right and b). As expected, each MKK also increased Fluc (Fig. 5a left), presumably via activation of an endogenous p38. Neither of the MKKs had any effect on cell growth (Fig. 5c). These results strongly suggest that inhibition of Rluc by p38 $\delta$ is a specific rather than indiscriminate effect.

The ability of p38 to inhibit the Rluc HSV-TK promoter was not empirically determined by us, but multiple reports show that HSV-TK promoters, including those driving Renilla, can be perturbed by multiple experimental conditions [61-64]. These include the expression of the Sp1 transcription factor [64], which is upregulated by $\mathrm{p} 38$ [65]. We consider the potential effects of $\mathrm{p} 38$ on the HSV-TK and SV40 heterologous promoters, as well as other elements of the L1 reporters, in greater detail in the discussion.

\section{Two non targeting control siRNAs differentially affect reported L1 activity}

While investigating the effect of $\mathrm{p} 38 \delta$ on $\mathrm{L} 1$ retrotransposition, we performed siRNA experiments using a SMARTpool mixture against p38 (Dharmacon, M003591-02-0005) and the NTC siRNA \#3 (Dharmacon). Although the siRNA against p38 dramatically reduced 
A

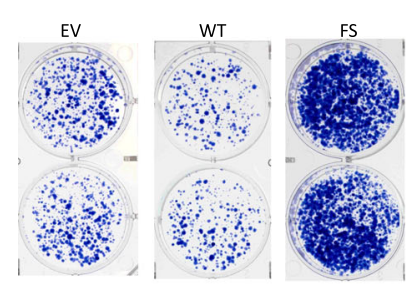

B

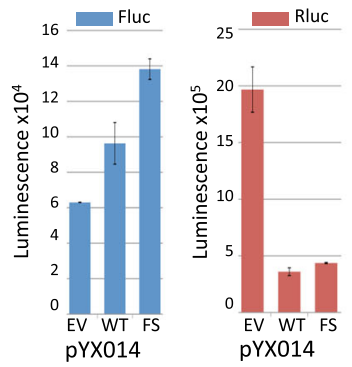

C

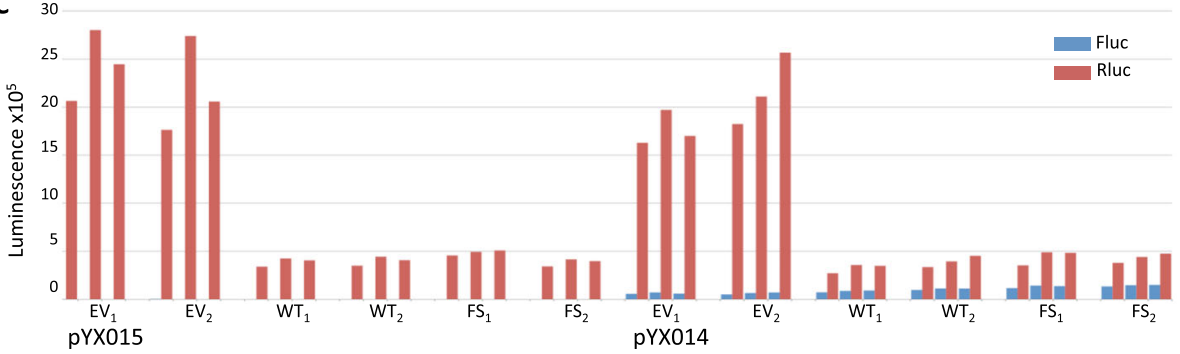

Fig. 4 p38 increases Fluc independent of a heterologous promoter. a Duplicate wells containing G418-resistant colonies resulting from transfection of HeLa cells with the L1 reporter JM101 in the presence of pcDNA mammalian expression vectors for: empty vector (EV), p388-WT (WT) or p388-F3324S (FS). b Mean Fluc (left) and Rluc (right) luminescence values obtained from lysates of HeLa cells transfected with the L1 reporter plasmid pYX014 in the presence of indicated pcDNA mammalian expression vectors. Averages were derived from raw data shown in (c) by first averaging technical replicates for each biological sample $(n=3)$, and averaging biological replicates; error bars represent SEM of biological samples, $n=2$. c Individual luminescence values are shown for Fluc (blue) and Rluc (red) used to calculate averages in (b); technical replicates are side-by-side; biological replicates are indicated with subscripts

the number of G418-resistant colonies relative to NTC \#3, RT-PCR showed no significant knockdown of the p38 $\delta$ transcript (data not shown). Interestingly, however, NTC \#3 considerably increased colony density relative to the mock control (Fig. 6a left). EGFP fluorescence from cells pretreated with siRNA prior to transfection suggested that the siRNA had little impact on transfection efficiency (Fig. 6a right). Given these unexpected results, we tested an additional control siRNA, NTC \#5, also from Dharmacon. In marked contrast to NTC \#3, NTC \#5 dramatically reduced G418-resistant colonies relative to the mock control (Fig. $6 \mathrm{~b}$ top). Neither NTC dramatically affected cell growth, though NTC \#3 had a slight inhibitory effect (Fig. 6b bottom). It is notable that unlike p38 $\delta$-WT, the NTC siRNAs exerted their respective effects similarly on both Fluc luminescence and G418resistant colony formation (Fig. 6b top, c left and d). However, L1 activity as reported by the Fluc/Rluc ratio appears to be decreased by NTC \#3 rather than increased (Fig. 6c). We did not further investigate potential causes for these results. Information on Dharmacon's website states that each NTC is reported to contain a minimum of 4 mismatches to all human, mouse and rat genes and to have minimal effects in genome-wide targeting via microarray analyses. We did not test Dharmacon's NTC \#1, as it was reported to increase cell growth (personal communication, Dharmacon), nor NTC \#2 or \#4 due to their targeting of Firefly luciferase (Dharmacon website).

\section{Discussion}

Engineered L1 reporter assays have tremendously advanced the field of L1 research, allowing investigators to examine key details of the retrotransposition process [66]. Through mutational analyses, critical amino acids in ORF1p and ORF2p have been identified, leading to a greater understanding of the form and functions of these proteins and their roles in L1 retrotransposition. Investigations of L1 insertion sites, $5^{\prime}$ truncations, untranslated regions, native L1 promoters and the poly (A) tail have all been made possible by these assays, as have numerous comparative evolutionary studies of extinct L1 fossils in the human and mouse genomes. Our own work on the role of ORF1p phosphorylation would not have been possible without these reporters.

Importantly, we have not observed variation in relative differences between an L1-WT control and any L1 mutant in our history of working with L1 reporter plasmids. In other words, any mutant L1 construct we have made consistently exhibits the same degree of change in G418-resistant colonies relative to a WT control within a given experiment, independent of differences in cell populations. Thus, the L1 reporters are particularly reliable for investigating cis aspects of L1-the purpose for which the original reporter was designed. However, the results presented here strongly suggest that data derived from L1 reporters when used in conjunction with exogenous gene expression or siRNA to investigate the roles of host factors may be challenging to interpret. Although we have not exhaustively investigated possible 


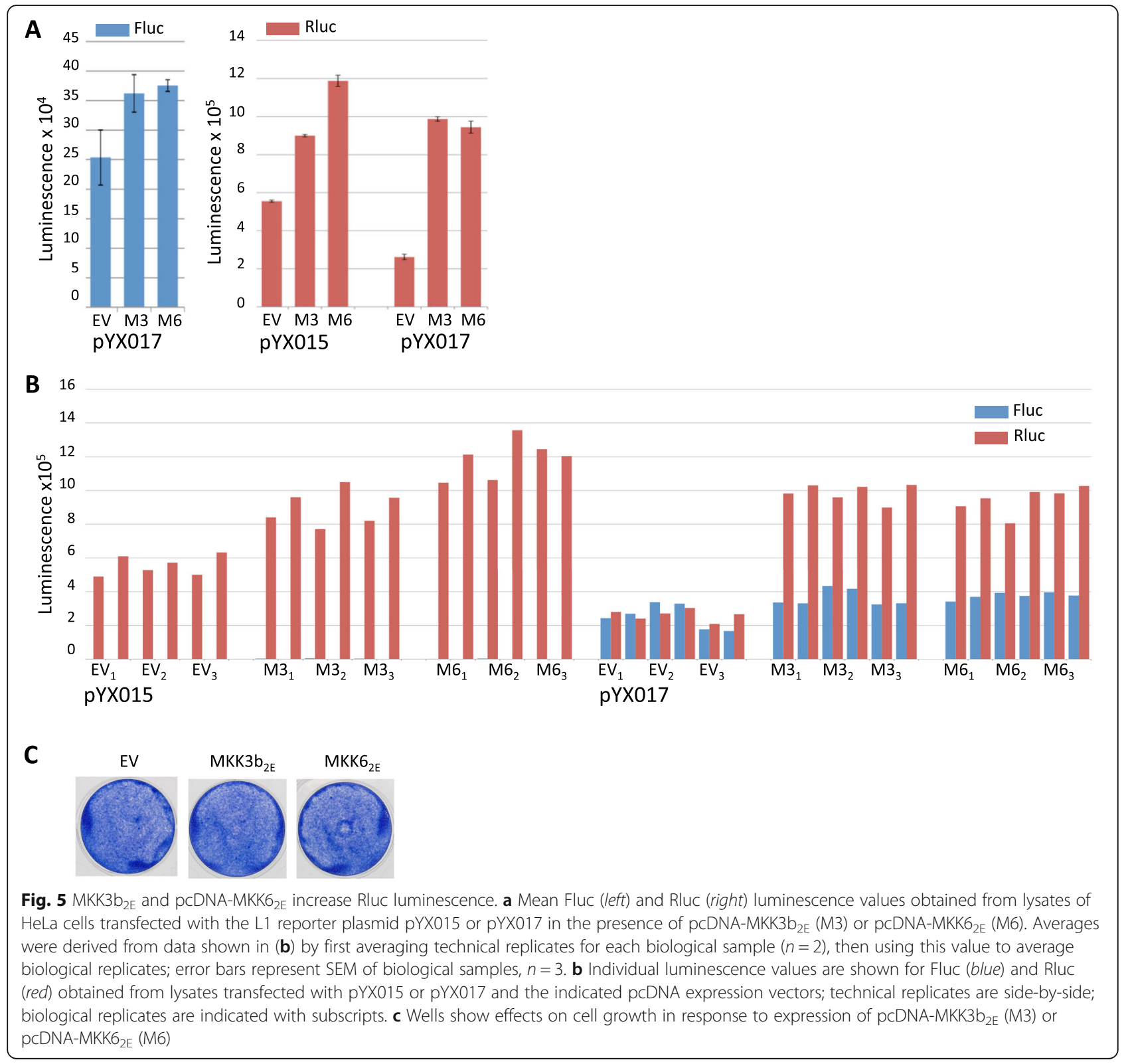

factors that would account for our results, we feel these data are nonetheless informative and potentially timesaving for other researchers intending to use these approaches to investigate interactions between L1 and its host.

Our efforts to determine the effect of p38 $\delta$ on L1 retrotransposition using engineered L1 reporters underscore the complexities inherent in such endeavors. The p38 signaling pathway itself is extremely complex, with different isoforms having unique, overlapping or competing functions depending on the cell type, or even within the same cell under different conditions [35, 67-69]. This complexity is compounded by the possibility that different p38 isoforms may have competing specificities and functional outcomes on ORF1p and other substrates relevant to L1 activity, as well as on heterologous promoters in $\mathrm{L} 1$ reporters.

A case in point is the repression of Rluc by exogenous p388. Previous reports show that p38 can activate late HSV promoters [70] as well as the transcription factor Sp1 [65], which both binds [71] and activates the HSV-TK promoter $[61,64]$. These studies would suggest that if p38 $\delta$ had an effect on HSV-TK, it would be activation, not repression. However, this assumption would be an oversimplification given the complexity of p38 signaling and reports that p38 isoforms can compete with one other with opposing effects [68]. An alternative possibility is that over-expression of exogenous p38 $\delta$ perturbed constitutive 


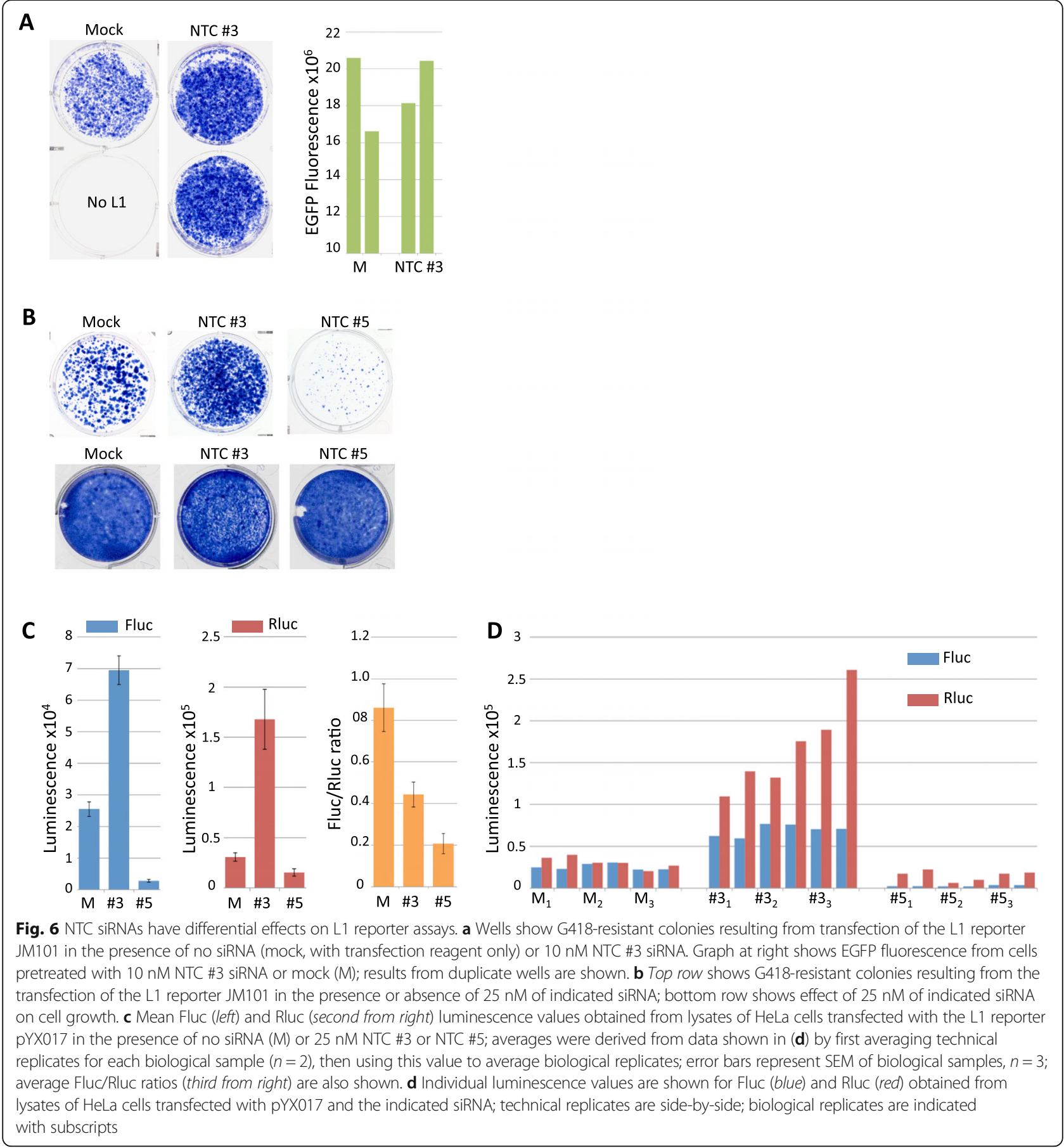

activation of the HSV-TK promoter by interfering with a different endogenous p38 isoform. This possibility is supported by two observations. First, each p $38 \delta$ construct repressed Rluc luminescence despite the fact that each has widely varying catalytic activities in vitro as well as different effects on L1 activation. Equivalent effects from each p38 $\delta$ construct would be expected only if the effect were mediated by something other than their catalytic kinase activity; e.g., competition for docking interactions with limiting regulatory factors required by other $\mathrm{p} 38$ isoforms. Second, since MKK3b-2E and MKK6-2E selectively activate only p38 isoforms [72], their activation of Rluc strongly suggests that HSV-TK is indeed activated by an endogenous p38 isoform, but not p38 8 . Combined, these data indicate that the ability of both active and inactive exogenous $\mathrm{p} 38 \delta$ to repress the HSV-TK promoter derives from competition for host regulatory proteins by another, endogenous p38 isoform. 
While most of our focus here has been on possible sources of artifact arising from the single vector dual luciferase assay, p38 $\delta$-WT and p38 8 -F324S similarly activated Fluc in those assays; it was only in the G418-based assay where contradictory results between $\mathrm{p} 38 \delta$-WT and F324S were observed, with significant inhibition of apparent retrotransposition in response to $\mathrm{p} 38 \delta$-WT but strong activation by F324S. Since p38 $\delta$-WT gave conflicting results in these assays, it may be worth discussing potentially relevant variations between the assays.

One notable difference is the lack of the Epstein-Barr nuclear antigen 1 (EBNA1) gene and the Epstein-Barr virus (EBV) origin of replication on the single vector dual luciferase reporters, which were not required due to the shorter experimental time relative to the G418-based assay [39]. EBNA1, however, contains multiple phosphorylation sites required for the maintenance of plasmids and transcriptional activation [73, 74]. Specifically, the EBNA1 nuclear localization sequence contains two S/T-P motifs, whose phosphorylation is required for nuclear import [73-75]. Although at least one of these motifs is thought to be targeted by CDKs [75], it is possible that phosphorylation of one or both S/T-P motifs is perturbed by exogenous p38 $\delta$-WT expression via competition for regulatory factors.

Another difference between the two assays is their respective reporter genes. The G418-based assay relies on expression of APH (3')-II to monitor L1 retrotransposition. However, in addition to inactivating aminoglycosides via phosphorylation, two APH isoforms have also been found to phosphorylate proteins. Although it is not known whether the neomycin resistance gene APH (3')-II or the hygromycin resistant gene APH (4)-I, also present on JM101, can similarly target cellular proteins, caution has been urged in their use as selectable markers if such activity might interfere with the experimental design [76].

A source of potential artifact for both assays is the SV40 promoter, which drives the neo and Fluc reporter cassettes. As noted earlier, p38 is known to activate the transcription factor Sp1, which in addition to binding the HSV-TK promoter also binds and activates the SV40 early promoter [77]. Moreover, the SV40 promoter contains binding sites for AP-1 transcription factors [78, 79], which are activated by the isoform $\mathrm{p} 38 \beta$ but can be inhibited by p38y or p388 [68]. Thus, perturbed expression, in either direction, of an already spliced and integrated Fluc gene could falsely report on retrotransposition events. It is unclear, however, whether an increase above a given baseline expression of APH (3')-II would alter colony viability or growth during G418 selection. Also of note, a recent study of the effects of heavy metals on L1 found that cobalt increased the activity of the SV40 promoter in HeLa cells but decreased its activity in human fibroblasts and the human neuroblastoma cell line BE (2)-M17 [80], indicating that heterologous promoters can be differentially affected by the same variables in different cell lines. This raises the possibility that different clonal populations of the same cell type might also respond differentially to exogenous factors.

Regarding potential effects arising from the CMV promoter, although p38 $\delta$ did not appear to affect expression of the CMV-driven EGFP, we imaged EGFP expressing cells $24 \mathrm{~h}$ post transfection for the purpose of monitoring transfection efficiencies, whereas G418 selection was begun three days post transfection. Thus, though EGFP appeared to report equivalent transfection efficiencies, it may not have accurately reflected cumulative effects of p38 $\delta$ on a CMV promoter after $72 \mathrm{~h}$. With respect to transfection efficiency controls, the potential for exogenous factors to impact these reporters remains an issue, as was demonstrated by the effects of $\mathrm{p} 38 \delta$ on Rluc luminescence, which is the transfection efficiency reporter for the luciferase assay, versus no effect on from $\mathrm{p} 38 \delta$ on EGFP fluorescence, which is also a common reporter for transfection efficiencies in a variety of assays.

The use of siRNA to probe the functions of cellular genes is a common technique, but the potential for offtarget effects is a major drawback. This is typically accounted for by using NTC siRNA, with the assumption that NTC and target siRNAs produce equivalent off-target effects. While this may be true for some experimental systems, the dramatically different effects of NTC \#3 and NTC \#5 on L1 reporter output suggest a potential problem when these methods are used together. First, interpretations regarding the effect of a targeting siRNA based on comparison to a given NTC would be skewed if the siRNAs produced dissimilar off-target artifacts. This is true even if one confirms knockdown of the target gene. For example, if the target siRNA knocks down a gene of interest (GOI) by $50 \%$ and decreases L1 retrotransposition by $50 \%$, one might conclude that knocking down the GOI decreases L1 activity if control siRNA \#3 was the nontargeting control. In contrast, if one happened to use control siRNA \#5, the conclusion would have been the opposite; i.e. that knockdown increased L1 activity.

In addition, it is possible that targeting siRNAs could induce the same types of artifacts we observed with the NTC siRNAs. For example, despite a hypothetical parallel 50\% knockdown of the GOI and L1 activity, the decrease in L1 activity may have been due solely to offtarget effects unrelated to gene knockdown. Similarly, it may be possible that off-target effects that increase apparent L1 activity could mask a genuine inhibitory effect mediated by gene knockdown. Our data with NTC \#3 and \#5 show that it is unreliable to control for such offtarget effects by using non-targeting control siRNAs alone, as their effects can vary dramatically and may not be equivalent to those induced by targeting siRNAs. The most well- established method for confirming that results 
from targeting siRNA are due to GOI knockdown is the cotransfection of siRNA-resistant rescue plasmids. However, the interpretation of these results may still be complex in certain situations, as evidenced by our finding that $\mathrm{p} 38 \delta$-WT can both repress and activate L1 activity in different assays and cellular contexts.

In addition, our finding that non-targeting control siRNAs may affect L1 retrotransposition may have relevance not only for interpreting L1 assays but also for the development of therapeutic siRNA, a treatment option currently being optimized for numerous conditions including cancer [81-83]. As L1 is thought to have deleterious effects, caution is warranted in the design and testing of candidate molecules intended for clinical use.

Effects on heterologous promoters can be monitored in order to select one unaffected by experimental conditions. However, as some L1 reporters have up to three such promoters and may also be susceptible to artifacts arising from EBNA1 and the EBV origin of replication, this approach could be costly in terms of labor and resources and is therefore impractical for high throughput screening utilizing multiple experimental conditions. However, assuming suitable promoters could be identified for each experimental condition, a combination of native and constitutive L1 promoters with corresponding assays to monitor cell growth may be employed to successfully identify effects on L1 activity.

Several recently developed methods may offer some alternatives [84, 85]. The L1 element amplification protocol (LEAP assay) allows investigation of in vitro ORF2p enzymatic activity from L1 RNP particles purified from cells expressing engineered L1 reporters [86, 87]. The addition of purified host factors to these reactions would allow investigation of direct effects on ORF2p reverse transcriptase activity while avoiding some of the issues described herein. Next-generation sequencing methods [85, 88] including retrotransposon capture sequencing (RC-seq) [89, 90], as well as novel approaches for validation such as droplet digital PCR [91], offer the possibility of examining endogenous L1 elements in their native chromatin environment. These technical advances should facilitate investigation of the host factors that delimit L1 tissue specificity and various aspects of retrotransposition.

\section{Conclusions}

Our results indicate that the use of exogenous gene expression or siRNA with engineered L1 reporter assays may introduce confounding variables. Thus, investigation of the roles of host factors in L1 retrotransposition when using these techniques will require extra efforts to ensure that observed results are not artifacts.

\section{Methods \\ Plasmid construction}

Bacterial expression vectors for ORF1p (pET32a $\Delta N$ ORF1-6xHis) were made as follows. First, an existing ORF1 vector [92] with the backbone of pET32a was altered to remove the following: the pET32a N-terminal TRX and 6xHis tags, an engineered TEV sequence that had previously destroyed the multiple cloning region, a truncated ORF1 mutant and remnant sequence $3^{\prime}$ to ORF1 that was retained from prior subcloning. A remaining 3' EcoRI site and the C-terminal 6xHis tag were left intact, and BamH1 site was inserted $5^{\prime}$ of the EcoRI site. These changes were made using the QuikChange II kit (Agilent) with the forward deletion primer 5'TTAACTTTAAGAAGGAGATATACATGGATCCAAT CCCGGGACGCGTG and reverse deletion primer 5' CACGCGTCCCGGGATTGGATCCATGTATATCTCCT TCTTAAAGTTAA. The resulting clone was designated $\mathrm{pET} 32 \mathrm{a} \triangle \mathrm{N}$. Full-length ORF1 PCR-generated amplicons were created from the previously described pORF1Flag mammalian expression vector [31] using a highfidelity DNA polymerase with the forward primer $5^{\prime}$ CGCGGATCCATGGGGAAAAAACAGAACAG containing a 5' BamH1 site, and reverse primer 5' GCCGGAATTCGCCGCCGCCCATTTTGGCATGATTT TGC, which introduced a spacer of three glycines between the end of ORF1 and the 3' EcoRI sequence (the Flag sequence was not retained). The ORF1p amplicon was inserted into pET32a $\Delta \mathrm{N}$ via the BamH1 and EcoRI sites. The BamH1 site was subsequently deleted to move the ATG start site of ORF1 to an optimal distance from the ribosomal binding site in pET32a $\triangle \mathrm{N}$ and destroy an alternate out-of-frame ATG start site that encompassed the 5' G of the BamH1 site. These changes were made using the QuikChange II kit (Agilent) with the forward primer 5' GAAATAATTTTGTTTAACTTTAAGAAGGAGATATACATATGGGGAAAAAACAGAACAG and the reverse primer 5'CTGTTCTGTTTTTTCCCCATATGTATATCTCC TTCTTAAAGTTAAACAAAATTATTTC. In an attempt to reduce translation initiation at internal non-canonical Shine-Dalgarno sequences in ORF1, we also created silent mutations at D123 and N126, changing the existing codons to GAC and AAC, respectively. ORF1p S/T-P motif mutations were created using sequential site-directed mutagenesis with the QuikChange II kit (Agilent).

Bacterial expression plasmids for p38 8 -F324S and D176A (pRSET-A-6xHis-p388-StrepII) were made by first generating a $\mathrm{p} 38 \delta$-WT amplicon via PCR using a high-fidelity polymerase and the forward primer $5^{\prime}$ CGCGGATCCGCAATGAGCCTCATCCGGAAAAAGG GCTTCTACAAGCAGG and reverse primer 5'GCCG GAATTCTCACTTCTCGAACTGGGGGTGGCTCCAT GCGCCCAGCTTCATGCCACTCCG on the Addgene template plasmid \# 20523 (pWZL Neo Myr Flag 
MAPK13, a gift from William Hahn \& Jean Zhao [93]). The amplicon containing a 5' BamHI and Kozak sequence and a 3' Gly/Ala spacer upstream of a StrepII tag, stop codon and EcoRI site was then inserted into pRSET-A (ThermoFisher) via the BamHI and 3' EcoRI sites in the multiple cloning region. Point mutations were created via site-directed mutagenesis with the QuikChange II kit (Agilent).

The mammalian expression vector for $\mathrm{p} 38 \delta-\mathrm{WT}$ (pcDNA-Zeo (3.1+)-p38 $\delta$-StrepII) was made by PCR amplification of the Addgene plasmid \# 20523 [93] using the same forward and reverse primers noted above for making pRSET-A-6xHis-p38 8 -StrepII, followed by insertion into the multiple cloning region of pcDNA 3.1/Zeo (+) (ThermoFisher). Point mutations to make F324S and D176A were created via site-directed mutagenesis with the QuikChange II kit (Agilent).

Mammalian expression vectors for $\mathrm{MKK} \mathrm{b}_{2 \mathrm{E}}$ (pcDNA3 Flag MKK3b (Glu) [58]; Addgene plasmid \# 50449) and $\mathrm{MKK}_{2 \mathrm{E}}$ (pcDNA3-Flag MKK6 (Glu) [60]; Addgene plasmid \# 13518) were both gifts from Roger Davis.

All cloned inserts were verified with DNA sequencing. DNA intended for cell culture transfections was purified using the endotoxin-free NucleoBond Xtra Midi plasmid DNA purification kit (Macherey-Nagel).

\section{Protein expression}

ORF1p proteins were expressed in Rosetta (DE3) cells (Novagen) transformed with pET32a $\triangle$ N-ORF1-His. Overnight starter cultures of $15-25 \mathrm{ml} \mathrm{LB}$ medium with $100 \mu \mathrm{g} / \mathrm{ml}$ ampicillin and $34 \mu \mathrm{g} / \mathrm{ml}$ chloramphenicol were grown at $37{ }^{\circ} \mathrm{C}$ on a rotary shaker at $250 \mathrm{rpm}$. The following day, cultures were expanded 20 to 50 fold with LB medium containing the indicated antibiotics and grown at $37{ }^{\circ} \mathrm{C}$ on a rotary shaker at $250 \mathrm{rpm}$ to an $\mathrm{OD}_{600}$ of approximately 0.6 . Cultures were then induced with $1 \mathrm{mM}$ isopropyl-beta-D-thiogalactopyranoside (IPTG), grown for an additional 4-6 h, pelleted via centrifugation and frozen at $-80{ }^{\circ} \mathrm{C}$. At the time of purification, cells were thawed and resuspended in $5 \mathrm{ml}$ per gram pellet of a buffer containing $100 \mathrm{mM}$ Tris- $\mathrm{HCl}$ (pH 8.0), $100 \mathrm{mM} \mathrm{NaCl}$, and $1 \mathrm{mg} / \mathrm{ml} \mathrm{lysozyme} \mathrm{and} \mathrm{incubated} \mathrm{on} \mathrm{ice} \mathrm{for} 30 \mathrm{~min}$. Following lysozyme digest, lysates were supplemented with $400 \mathrm{mM} \mathrm{NaCl}$ (for final concentration of $500 \mathrm{mM}$ ), $2 \mathrm{mM}$ dithiothreitol (DTT) and $15 \mathrm{mM}$ imidazole. The lysates were pulled through a 19-21gauge syringe approximately 12 times and centrifuged at $10,000 \times \mathrm{g}$ at $4{ }^{\circ} \mathrm{C}$ for $20 \mathrm{~min}$. Cleared lysates were applied to Ni-NTA superflow resin (Qiagen) previously equilibrated with lysis buffer (post lysozyme concentrations), rotated for $1 \mathrm{~h}$ at $4{ }^{\circ} \mathrm{C}$, washed 4 times with $20 \mathrm{mM}$ Tris- $\mathrm{HCl}$ (pH 7.4), $500 \mathrm{mM} \mathrm{NaCl}$, and $25 \mathrm{mM}$ imidazole, then eluted 4 times with $20 \mathrm{mM}$ Tris- $\mathrm{HCl}$ (pH 7.4), $500 \mathrm{mM} \mathrm{NaCl}, 250 \mathrm{mM}$ imidazole, $10 \%$ glycerol and $2 \mathrm{mM}$ DTT at a ratio of $1 \mu \mathrm{l}$ elution buffer per $1 \mathrm{ml}$ of original culture volume. Proteins were dialyzed overnight against $50 \mathrm{mM}$ Tris- $\mathrm{HCl}(\mathrm{pH} 80)$, $350 \mathrm{mM} \mathrm{NaCl}, 15 \mathrm{mM} \mathrm{KCl}, 5 \mathrm{mM} \mathrm{MgCl} 2,20 \%$ glycerol, $2 \mathrm{mM} \mathrm{DTT}$, and $1 \mathrm{mM}$ phenylmethylsulfonyl fluoride (PMSF).

p388-F324S and p388-D176A proteins were expressed in Rosetta2 (DE3) cells (Novagen) transformed with pRSET-A-His-p38 $\delta$-StrepII and processed as described above for ORF1p except $150 \mathrm{mM} \mathrm{NaCl}$ was used in the dialysis buffers. Note: we found that omission of DTT in the elution and/or dialysis steps of $\mathrm{p} 38 \delta$ purification resulted in an inactive protein, consistent with a previous report [94].

All proteins were quantified via denaturing gel electrophoresis with a standard curve of bovine serum albumin followed by staining with Coomassie G-250 PageBlue (ThermoFisher) and analysis with ImageJ [95].

\section{Kinase assays}

In vitro kinase reactions contained $85 \mathrm{nM}$ p38 $\delta$ or $\mathrm{p} 38 \delta$ dialysis buffer and $200 \mu \mathrm{M}$ ORF1p in $50 \mathrm{mM}$ Tris- $\mathrm{HCl}$ (pH 7.4), $10 \mathrm{mM} \mathrm{MgCl} 2,0.1 \mathrm{mM}$ EGTA, $150 \mathrm{mM} \mathrm{NaCl}$, $2 \mathrm{mM}$ DTT, and $2 \mathrm{mM}$ ATP spiked with approximated $0.5 \times 10^{6}$ c.p.m./nmol $\left[\gamma^{-}{ }^{32} \mathrm{P}\right]$-ATP (PerkinElmer). Reactions were incubated at $37{ }^{\circ} \mathrm{C}$ for $15 \mathrm{~min}$ and stopped with the addition of loading buffer supplemented with EDTA to a final concentration of $50 \mathrm{mM}$. Samples were heated to $98{ }^{\circ} \mathrm{C}$ for $10 \mathrm{~min}$ then separated via denaturing gel electrophoresis. Gels were dried and exposed using Phosphorimaging.

\section{Cell culture}

HeLa-JVM cells (a kind gift from Dr. John Moran) were cultured in Dulbecco's Modified Eagle Media (DMEM) with high glucose and pyruvate (Gibco, ThermoFisher) supplemented with 10\% Fetal Bovine Serum (Gibco, ThermoFisher, certified heat inactivated, US origin) and 100 Units $/ \mathrm{ml}$ penicillin and $100 \mu \mathrm{g} / \mathrm{ml}$ streptomycin from a combined formulation (Gibco, ThermoFisher). The cells were maintained at $37^{\circ} \mathrm{C}$ in a standard incubator and passaged using 0.05\% Trypsin-EDTA (Gibco, ThermoFisher).

\section{L1 reporter assays}

Culture plates were seeded with HeLa-JVM cells in antibiotic-free DMEM with $10 \% \mathrm{FBS}$ at a density to achieve approximately $50 \%$ confluency in $24 \mathrm{~h}$, at which time cells were transfected using a ratio of $3 \mu$ l Fugene6 (Promega) per $1 \mu \mathrm{g}$ DNA. For the G418-based assay, cells were seeded in 6-well plates and transfected with $500 \mathrm{ng} \mathrm{JM101}$ and $500 \mathrm{ng}$ pcDNA per well, allowed to grow for $72 \mathrm{~h}$, then selected with media containing $400 \mu \mathrm{g} / \mathrm{ml}$ G418 sulfate (Geneticin, Gibco, ThermoFisher) for 10-12 days. Cells were then washed with 
phosphate buffered saline (PBS) and fixed with $2 \%$ formaldehyde and $0.2 \%$ glutaraldehyde in PBS for at least $30 \mathrm{~min}$ at room temperature. Cells were then washed twice with PBS, stained with KaryoMAX Giemsa (Gibco, ThermoFisher) for $1 \mathrm{~h}$ at room temperature, rinsed briefly twice with $50 \%$ ethanol and then water. For luciferase assays, cells were seeded in 24-well plates and transfected with $200 \mathrm{ng}$ of reporter and $200 \mathrm{ng}$ pcDNAp38 $\delta$ per well or $25 \mathrm{ng}$ pcDNA-MKK $3 \mathrm{~b}_{2 \mathrm{E}}$ or pcDNA$\mathrm{MKK}_{2 \mathrm{E}}$. Lysates were harvested 4 days post transfection and processed in 96-well plates with the Dual-Luciferase Reporter Assay System (Promega) according to manufacturer's protocol.

\section{Transfection efficiency assays}

HeLa-JVM cells were plated in 8-well glass bottom $\mu$-Slides (ibidi $\mathrm{GmbH}$, Martinsried, Germany) in antibiotic-free DMEM with $10 \%$ FBS at a density to achieve approximately $60 \%$ confluency per well in $24 \mathrm{~h}$. Wells with siRNA were reverse transfected as described in the following section. After a 24-h incubation, cells were transfected as described above with a pcDNA-EGFP expression plasmid (for siRNA wells) or cotransfected with pcDNA-EGFP and each pcDNA-p38 $\delta$ expression plasmid. The ratio of DNA to surface area was identical to that used in the 6-well plates. After $24 \mathrm{~h}$, cells were rinsed twice with PBS, then DMEM sans phenol red plus 10\% FBS was added to each well. Cells were visualized with a Keyence BioRevo BZ-II 9000 digital microscope fitted with a Nikon PlanApo 4×/0.20 objective lens and 49002 ET-EGFP filter set from Chroma (Bellows Falls, VT). Tiled images covering approximately $70 \%$ of each well were stitched with Keyence BZ-II Analyzer software, and total fluorescence in each stitched image was quantified in Fiji software using the Integrated Density function.

\section{siRNA knockdown}

HeLa-JVM cells were plated in antibiotic-free DMEM with $10 \%$ FBS at a density to achieve approximately $60 \%$ confluency in $24 \mathrm{~h}$ and reverse transfected per manufactures' protocol using Lipofectamine RNAiMAX (ThermoFisher) at a ratio of $1 \mu$ l RNAiMAX per 8 pmols siRNA. All siRNAs were purchased from Dharmacon: NTC \#3, NTC \#5 and SMARTpool siRNA against p38 (Dharmacon, M-003591-02-0005). Following reverse transfection, cells were incubated for $24 \mathrm{~h}$, then siRNAcontaining media was removed and replaced with fresh antibiotic-free plating media with 10\% FBS at the time of transfection with L1 reporters as described above.

\section{Abbreviations}

APH(3')-II: Aminoglycoside 3'-phosphotransferase-II; CDKs: Cyclin dependent kinases; CMV: Cytomegalovirus; DTT: Dithiothreitol; EBNA1: Epstein-Barr nuclear antigen 1; EBV: Epstein-Barr virus; EGFP: Enhanced green fluorescent protein; FBS: Fetal bovine serum; Fluc: Firefly luciferase; GSK3: Glycogen synthase kinase 3; GST-ATF2: glutathione S-transferase activating transcription factor 2; HSV-TK: Herpes simplex virus thymidine kinase; IPTG: Isopropyl-betaD-thiogalactopyranoside; L1, LINE-1: Long INterspersed Element-1; LEAP assay: L1 element amplification protocol; MAPKKs: MAPK-kinases; MAPKs: Mitogen-activated protein kinases; NTC: Non-targeting control; PDPKs: Proline-directed protein kinases; PMSF: Phenylmethylsulfonyl fluoride; RC-seq: Retrotransposon capture sequencing; Rluc: Renilla luciferase; S/TP: Serine/threonine-proline; SA: Splice acceptor; SD: Splice donor; SINES: Short-INterspersed repeat Elements; siRNA: Small interfering RNA; SV40: Simian virus 40; UTR: Untranslated region

\section{Acknowledgements}

We would like to thank Dr. Charles E. Jones, Dr. Sandy Martin and Dr. Anthony V. Furano for their critical reading of the manuscript and useful discussion. We also thank Dr. John Moran for his gifts of JM101 and HeLa-JVM cells, Dr. Wenfeng An for his gifts of L1 dual luciferase reporters, and Dr. Birong Shen for her gift of the EGFP plasmid. We also thank Jeff M. Reece from the NIDDK light microscopy core for his invaluable help analyzing the EGFP data.

\section{Funding}

This work was supported by the laboratory of Anthony V. Furano at the National Institute of Diabetes and Digestive and Kidney Diseases, National Institutes of Health; Grant 1-ZIA-DK057601-19.

Availability of data and materials

Not applicable.

Authors' contributions

Both authors contributed equally to the experimental work. PRC drafted the manuscript, and GTT assisted in revisions and editing.

Consent for publication

All authors and acknowledged individuals have given their consent.

\section{Competing interests}

The authors declare they have no competing interests.

Ethics approval and consent to participate

Not applicable.

\section{Author details}

'Laboratory of Cell and Molecular Biology, National Institute of Diabetes and Digestive and Kidney Diseases, National Institutes of Health, 8 Center Drive, Bethesda, MD 20892, USA. ${ }^{2}$ National Institute of Child Health and Human Development, National Institutes of Health, 35 Convent Drive, Bethesda, MD 20892, USA

Received: 16 April 2016 Accepted: 4 November 2016

Published online: 22 November 2016

\section{References}

1. Treangen TJ, Salzberg SL. Repetitive DNA and next-generation sequencing: computational challenges and solutions. Nat Rev Genet. 2012;13(1):36-46.

2. Kazazian Jr HH, Goodier JL. LINE drive. retrotransposition and genome instability. Cell. 2002;110(3):277-80.

3. Babatz TD, Burns KH. Functional impact of the human mobilome. Curr Opin Genet Dev. 2013;23(3):264-70.

4. Faulkner GJ. Retrotransposons: mobile and mutagenic from conception to death. FEBS Lett. 2011;585(11):1589-94.

5. Boissinot S, Davis J, Entezam A, Petrov D, Furano AV. Fitness cost of LINE-1 (L1) activity in humans. Proc Natl Acad Sci U S A. 2006;103(25):9590-4.

6. Rosser JM, An W. L1 expression and regulation in humans and rodents. Front Biosci. 2012:4:2203-25.

7. Kano H, Godoy I, Courtney C, Vetter MR, Gerton GL, Ostertag EM, Kazazian Jr $\mathrm{HH}$. L1 retrotransposition occurs mainly in embryogenesis and creates somatic mosaicism. Genes Dev. 2009;23(11):1303-12.

8. van den Hurk JA, Meij IC, Seleme MC, Kano H, Nikopoulos K, Hoefsloot LH, Sistermans EA, de Wijs IJ, Mukhopadhyay A, Plomp AS, et al. L1 retrotransposition can occur early in human embryonic development. Hum Mol Genet. 2007;16(13):1587-92. 
9. Arokium H, Kamata M, Kim S, Kim N, Liang M, Presson AP, Chen IS. Deep sequencing reveals low incidence of endogenous LINE-1 retrotransposition in human induced pluripotent stem cells. PLoS One. 2014;9(10):e108682.

10. Wissing S, Munoz-Lopez M, Macia A, Yang Z, Montano M, Collins W, GarciaPerez JL, Moran JV, Greene WC. Reprogramming somatic cells into iPS cells activates LINE-1 retroelement mobility. Hum Mol Genet. 2012;21(1):208-18.

11. Reilly MT, Faulkner GJ, Dubnau J, Ponomarev I, Gage FH. The role of transposable elements in health and diseases of the central nervous system. J Neurosci. 2013;33(45):17577-86.

12. Kurnosov AA, Ustyugova SV, Nazarov VI, Minervina AA, Komkov AY, Shugay M, Pogorelyy MV, Khodosevich KV, Mamedov IZ, Lebedev YB. The evidence for increased L1 activity in the site of human adult brain neurogenesis. PLOS One. 2015;10(2):e0117854.

13. Thomas CA, Paquola AC, Muotri AR. LINE-1 retrotransposition in the nervous system. Annu Rev Cell Dev Biol. 2012;28:555-73.

14. Richardson SR, Morell S, Faulkner GJ. L1 retrotransposons and somatic mosaicism in the brain. Annu Rev Genet. 2014;48:1-27.

15. Upton KR, Gerhardt DJ, Jesuadian JS, Richardson SR, Sanchez-Luque FJ, Bodea GO, Ewing AD, Salvador-Palomeque C, van der Knaap MS, Brennan PM, et al. Ubiquitous L1 mosaicism in hippocampal neurons. Cell. 2015; 161(2):228-39

16. Carreira PE, Richardson SR, Faulkner GJ. L1 retrotransposons, cancer stem cells and oncogenesis. The FEBS J. 2014;281(1):63-73.

17. Rodic N, Burns KH. Long interspersed element-1 (LINE-1): passenger or driver in human neoplasms? PLoS Genet. 2013;9(3):e1003402.

18. Helman E, Lawrence MS, Stewart C, Sougnez C, Getz G, Meyerson M. Somatic retrotransposition in human cancer revealed by whole-genome and exome sequencing. Genome Res. 2014;24(7):1053-63.

19. Tubio JM, Li Y, Ju YS, Martincorena I, Cooke SL, Tojo M, Gundem G, Pipinikas $C P$, Zamora J, Raine K. Mobile DNA in cancer. Extensive transduction of nonrepetitive DNA mediated by $L 1$ retrotransposition in cancer genomes. Science. 2014;345(6196):1251343.

20. Beck CR, Garcia-Perez JL, Badge RM, Moran JV. LINE-1 elements in structural variation and disease. Annu Rev Genomics Hum Genet. 2011;12:187-215.

21. Hancks DC, Kazazian Jr HH. Active human retrotransposons: variation and disease. Curr Opin Genet Dev. 2012;22(3):191-203.

22. Kaer K, Speek M. Retroelements in human disease. Gene. 2013;518(2):231-41.

23. Belancio VP, Hedges DJ, Deininger P. Mammalian non-LTR retrotransposons: for better or worse, in sickness and in health. Genome Res. 2008;18(3):343-58.

24. Gifford WD, Pfaff SL, Macfarlan TS. Transposable elements as genetic regulatory substrates in early development. Trends Cell Biol. 2013;23(5):218-26.

25. Emera D, Wagner GP. Transposable element recruitments in the mammalian placenta: impacts and mechanisms. Brief Funct Genomics. 2012;11(4):267-76.

26. Macia A, Blanco-Jimenez E, Garcia-Perez JL. Retrotransposons in pluripotent cells: Impact and new roles in cellular plasticity. Biochim Biophys Acta. 2015; 1849(4):417-26.

27. Roberts JT, Cardin SE, Borchert GM. Burgeoning evidence indicates that microRNAs were initially formed from transposable element sequences. Mob Genet Elements. 2014;4:e29255.

28. Mita $\mathrm{P}$, Boeke JD. How retrotransposons shape genome regulation. Curr Opin Genet Dev. 2016;37:90-100.

29. McLaughlin Jr RN, Young JM, Yang L, Neme R, Wichman HA, Malik HS. Positive selection and multiple losses of the LINE-1-derived L1TD1 gene in mammals suggest a dual role in genome defense and pluripotency. PLoS Genet. 2014;10(9):e1004531.

30. Chuong EB, Elde NC, Feschotte C. Regulatory evolution of innate immunity through co-option of endogenous retroviruses. Science. 2016;351(6277):1083-7.

31. Cook PR, Jones CE, Furano AV. Phosphorylation of ORF1p is required for $L 1$ retrotransposition. Proc Natl Acad Sci U S A. 2015;112(14):4298-303.

32. Ishizaka Y, Okudaira N, Tamura M, lijima K, Shimura M, Goto M, Okamura T. Modes of retrotransposition of long interspersed element-1 by environmental factors. Front Microbiol. 2012;3:191.

33. Okudaira N, lijima K, Koyama T, Minemoto Y, Kano S, Mimori A, Ishizaka Y. Induction of long interspersed nucleotide element-1 (L1) retrotransposition by 6-formylindolo [3,2-b] carbazole (FICZ), a tryptophan photoproduct. Proc Natl Acad Sci U S A. 2010;107(43):18487-92.

34. Kuchen S, Seemayer CA, Rethage J, von Knoch R, Kuenzler P, Beat AM, Gay RE, Gay S, Neidhart M. The L1 retroelement-related $\mathrm{p} 40$ protein induces p38delta MAP kinase. Autoimmunity. 2004;37(1):57-65.

35. Zarubin T, Han J. Activation and signaling of the p38 MAP kinase pathway. Res. 2005;15(1):11-8.
36. Blom N, Sicheritz-Ponten T, Gupta R, Gammeltoft S, Brunak S. Prediction of post-translational glycosylation and phosphorylation of proteins from the amino acid sequence. Proteomics. 2004;4(6):1633-49.

37. Avitzour M, Diskin R, Raboy B, Askari N, Engelberg D, Livnah O. Intrinsically active variants of all human p38 isoforms. FEBS J. 2007;274(4):963-75.

38. Moran JV, Holmes SE, Naas TP, DeBerardinis RJ, Boeke JD, Kazazian Jr HH. High frequency retrotransposition in cultured mammalian cells. Cell. 1996;87(5):917-27.

39. Xie Y, Rosser JM, Thompson TL, Boeke JD, An W. Characterization of L1 retrotransposition with high-throughput dual-luciferase assays. Nucleic Acids Res. 2011;39(3):e16.

40. Niwa H, Yamamura K, Miyazaki J. Efficient selection for high-expression transfectants with a novel eukaryotic vector. Gene. 1991;108(2):193-9.

41. Mayor Jr F, Jurado-Pueyo M, Campos PM, Murga C. Interfering with MAP kinase docking interactions: implications and perspective for the p38 route. Cell Cycle. 2007;6(5):528-33.

42. Hsieh YH, Wu TT, Huang CY, Hsieh YS, Hwang JM, Liu JY. p38 mitogen-activated protein kinase pathway is involved in protein kinase Calpha-regulated invasion in human hepatocellular carcinoma cells. Cancer Res. 2007;67(9):4320-7.

43. Seternes OM, Johansen B, Hegge B, Johannessen M, Keyse SM, Moens U. Both binding and activation of p38 mitogen-activated protein kinase (MAPK) play essential roles in regulation of the nucleocytoplasmic distribution of MAPKactivated protein kinase 5 by cellular stress. Mol Cell Biol. 2002;22(20):6931-45.

44. Somwar R, Koterski S, Sweeney G, Sciotti R, Djuric S, Berg C, Trevillyan J, Scherer PE, Rondinone CM, Klip A. A dominant-negative p38 MAPK mutant and novel selective inhibitors of p38 MAPK reduce insulin-stimulated glucose uptake in 3 T3-L1 adipocytes without affecting GLUT4 translocation. J Biol Chem. 2002;277(52):50386-95.

45. Thandavarayan RA, Watanabe K, Ma M, Gurusamy N, Veeraveedu PT, Konishi T, Zhang S, Muslin AJ, Kodama M, Aizawa Y. Dominant-negative p38alpha mitogenactivated protein kinase prevents cardiac apoptosis and remodeling after streptozotocin-induced diabetes mellitus. Am J Physiol Heart Circ Physiol. 2009; 297(3):H911-919.

46. Twait $E$, Williard DE, Samuel I. Dominant negative p38 mitogen-activated protein kinase expression inhibits NF-kappaB activation in AR42J cells. Pancreatology. 2010;10(2-3):119-28.

47. Faust D, Dolado I, Cuadrado A, Oesch F, Weiss C, Nebreda AR, Dietrich C. p38alpha MAPK is required for contact inhibition. Oncogene. 2005;24(53):7941-5.

48. Streva VA, Faber ZJ, Deininger PL. LINE-1 and Alu retrotransposition exhibit clonal variation. Mob DNA. 2013;4(1):16.

49. Bruening W, Giasson B, Mushynski W, Durham HD. Activation of stressactivated MAP protein kinases up-regulates expression of transgenes driven by the cytomegalovirus immediate/early promoter. Nucleic Acids Res. 1998; 26(2):486-9.

50. Chen J, Stinski MF. Role of regulatory elements and the MAPK/ERK or p38 MAPK pathways for activation of human cytomegalovirus gene expression. J Virol. 2002;76(10):4873-85.

51. Radhakrishnan P, Basma H, Klinkebiel D, Christman J, Cheng PW. Cell typespecific activation of the cytomegalovirus promoter by dimethylsulfoxide and 5-aza-2'-deoxycytidine. Int J Biochem Cell Biol. 2008;40(9):1944-55.

52. Svensson RU, Barnes JM, Rokhlin OW, Cohen MB, Henry MD. Chemotherapeutic agents up-regulate the cytomegalovirus promoter: implications for bioluminescence imaging of tumor response to therapy. Cancer Res. 2007;67(21):10445-54.

53. Xiao J, Deng J, Lv L, Kang Q, Ma P, Yan F, Song X, Gao B, Zhang Y, Xu J. Hydrogen Peroxide Induce Human Cytomegalovirus Replication through the Activation of p38-MAPK Signaling Pathway. Viruses. 2015;7(6):2816-33.

54. Curtin JA, Dane AP, Swanson A, Alexander IE, Ginn SL. Bidirectional promoter interference between two widely used internal heterologous promoters in a late-generation lentiviral construct. Gene Ther. 2008;15(5):384-90.

55. Huliak I, Sike A, Zencir S, Boros IM. The objectivity of reporters: interference between physically unlinked promoters affects reporter gene expression in transient transfection experiments. DNA Cell Biol. 2012;31(11):1580-4.

56. Rosen H, Di Segni G, Kaempfer R. Translational control by messenger RNA competition for eukaryotic initiation factor 2. J Biol Chem. 1982;257(2):946-52.

57. Shearwin KE, Callen BP, Egan JB. Transcriptional interference-a crash course. Trends Genet. 2005;21(6):339-45.

58. Enslen $\mathrm{H}$, Brancho DM, Davis RJ. Molecular determinants that mediate selective activation of p38 MAP kinase isoforms. EMBO J. 2000;19(6):1301-11.

59. Enslen H, Raingeaud J, Davis RJ. Selective activation of p38 mitogenactivated protein (MAP) kinase isoforms by the MAP kinase kinases MKK3 and MKK6. J Biol Chem. 1998;273(3):1741-8. 
60. Raingeaud J, Whitmarsh AJ, Barrett T, Derijard B, Davis RJ. MKK3- and MKK6regulated gene expression is mediated by the p38 mitogen-activated protein kinase signal transduction pathway. Mol Cell Biol. 1996;16(3):1247-55.

61. Shifera AS, Hardin JA. Factors modulating expression of Renilla luciferase from control plasmids used in luciferase reporter gene assays. Anal Biochem. 2010;396(2):167-72.

62. Theile D, Spalwisz A, Weiss J. Watch out for reporter gene assays with Renilla luciferase and paclitaxel. Anal Biochem. 2013;437(2):109-10.

63. Ho CK, Strauss 3rd JF. Activation of the control reporter plasmids pRL-TK and PRL-SV40 by multiple GATA transcription factors can lead to aberrant normalization of transfection efficiency. BMC Biotechnol. 2004;4:10.

64. Osborne SA, Tonissen KF. pRL-TK induction can cause misinterpretation of gene promoter activity. Biotechniques. 2002;33(6):1240-2.

65. D'Addario M, Arora PD, McCulloch CA. Role of p38 in stress activation of Sp1. Gene. 2006:379:51-61.

66. Rangwala SH, Kazazian Jr HH. The L1 retrotransposition assay: a retrospective and toolkit. Methods. 2009;49(3):219-26.

67. Keshet $Y$, Seger $R$. The MAP kinase signaling cascades: a system of hundreds of components regulates a diverse array of physiological functions. Methods Mol Biol. 2010;661:3-38.

68. Pramanik R, Qi X, Borowicz S, Choubey D, Schultz RM, Han J, Chen G. p38 isoforms have opposite effects on AP-1-dependent transcription through regulation of c-Jun. The determinant roles of the isoforms in the p38 MAPK signal specificity. J Biol Chem. 2003;278(7):4831-9.

69. Risco A, Cuenda A. New Insights into the p38gamma and p38delta MAPK Pathways. J Signal Transduct. 2012;2012:520289.

70. Mezhir JJ, Advani SJ, Smith KD, Darga TE, Poon AP, Schmidt H, Posner MC, Roizman B, Weichselbaum RR. lonizing radiation activates late herpes simplex virus 1 promoters via the p38 pathway in tumors treated with oncolytic viruses. Cancer Res. 2005;65(20):9479-84.

71. Jones KA, Yamamoto KR, Tjian R. Two distinct transcription factors bind to the HSV thymidine kinase promoter in vitro. Cell. 1985:42(2):559-72.

72. Remy G, Risco AM, Inesta-Vaquera FA, Gonzalez-Teran B, Sabio G, Davis RJ, Cuenda A. Differential activation of p38MAPK isoforms by MKK6 and MKK3. Cell Signal. 2010;22(4):660-7.

73. Duellman SJ, Thompson KL, Coon JJ, Burgess RR. Phosphorylation sites of Epstein-Barr virus EBNA1 regulate its function. J Gen Virol. 2009;90(Pt 9):2251-9.

74. Kitamura R, Sekimoto T, Ito S, Harada S, Yamagata H, Masai H, Yoneda Y, Yanagi K. Nuclear import of Epstein-Barr virus nuclear antigen 1 mediated by NPI-1 (Importin alpha5) is up- and down-regulated by phosphorylation of the nuclear localization signal for which Lys379 and Arg380 are essential. J Virol. 2006;80(4):1979-91.

75. Kang MS, Lee EK, Soni V, Lewis TA, Koehler AN, Srinivasan V, Kieff E. Roscovitine inhibits EBNA1 serine 393 phosphorylation, nuclear localization, transcription, and episome maintenance. J Virol. 2011;85(6):2859-68.

76. Daigle DM, McKay GA, Wright GD. Inhibition of aminoglycoside antibiotic resistance enzymes by protein kinase inhibitors. J Biol Chem. 1997;272(40):24755-8.

77. Dynan WS, Tjian R. The promoter-specific transcription factor Sp1 binds to upstream sequences in the SV40 early promoter. Cell. 1983;35(1):79-87.

78. Lee W, Haslinger A, Karin M, Tjian R. Activation of transcription by two factors that bind promoter and enhancer sequences of the human metallothionein gene and SV40. Nature. 1987;325(6102):368-72.

79. Lee W, Mitchell P, Tjian R. Purified transcription factor AP-1 interacts with TPA-inducible enhancer elements. Cell. 1987;49(6):741-52.

80. Habibi L, Shokrgozar MA, Tabrizi M, Modarressi MH, Akrami SM. Mercury specifically induces LINE-1 activity in a human neuroblastoma cell line. Mutat Res Genet Toxicol Environ Mutagen. 2014;759:9-20.

81. Young SW, Stenzel M, Jia-Lin Y. Nanoparticle-siRNA: A potential cancer therapy? Crit Rev Oncol Hematol. 2016;98:159-69.

82. Haussecker D. Current issues of RNAi therapeutics delivery and development. J Control Release. 2014;195:49-54.

83. Ren YJ, Zhang Y. An update on RNA interference-mediated gene silencing in cancer therapy. Expert Opin Biol Ther. 2014;14(11):1581-92.

84. Garcia-Perez JL, editor. Transposons and Retrotransposons: Methods and Protocols. New York: Springer; 2016.

85. Xing J, Witherspoon DJ, Jorde LB. Mobile element biology: new possibilities with high-throughput sequencing. Trends Genet. 2013;29(5):280-9.

86. Kopera HC, Flasch DA, Nakamura M, Miyoshi T, Doucet AJ, Moran JV. LEAP. L1 Element Amplification Protocol. Methods Mol Biol. 2016;1400:339-55.

87. Kulpa DA, Moran JV. Cis-preferential LINE-1 reverse transcriptase activity in ribonucleoprotein particles. Nat Struct Mol Biol. 2006;13(7):655-60.
88. Streva VA, Jordan VE, Linker S, Hedges DJ, Batzer MA, Deininger PL. Sequencing, identification and mapping of primed L1 elements (SIMPLE) reveals significant variation in full length $\mathrm{L} 1$ elements between individuals. BMC Genomics. 2015;16:220.

89. Baillie JK, Barnett MW, Upton KR, Gerhardt DJ, Richmond TA, De Sapio F, Brennan PM, Rizzu P, Smith S, Fell M, et al. Somatic retrotransposition alters the genetic landscape of the human brain. Nature. 2011;479(7374):534-7.

90. Klawitter S, Fuchs NV, Upton KR, Munoz-Lopez M, Shukla R, Wang J, GarciaCanadas M, Lopez-Ruiz C, Gerhardt DJ, Sebe A, et al. Reprogramming triggers endogenous L1 and Alu retrotransposition in human induced pluripotent stem cells. Nat comm. 2016;7:10286.

91. White TB, McCoy AM, Streva VA, Fenrich J, Deininger PL. A droplet digital PCR detection method for rare L1 insertions in tumors. Mob DNA. 2014;5(1):30.

92. Callahan KE, Hickman AB, Jones CE, Ghirlando R, Furano AV. Polymerization and nucleic acid-binding properties of human L1 ORF1 protein. Nucleic Acids Res. 2012;40(2):813-27.

93. Boehm JS, Zhao JJ, Yao J, Kim SY, Firestein R, Dunn IF, Sjostrom SK, Garraway LA, Weremowicz S, Richardson AL, et al. Integrative genomic approaches identify IKBKE as a breast cancer oncogene. Cell. 2007;129(6):1065-79.

94. Templeton DJ, Aye MS, Rady J, Xu F, Cross JV. Purification of reversibly oxidized proteins (PROP) reveals a redox switch controlling p38 MAP kinase activity. PLoS One. 2010;5(11):e15012.

95. Schneider CA, Rasband WS, Eliceiri KW. NIH Image to ImageJ: 25 years of image analysis. Nat Methods. 2012;9(7):671-5.

\section{Submit your next manuscript to BioMed Central and we will help you at every step:}

- We accept pre-submission inquiries

- Our selector tool helps you to find the most relevant journal

- We provide round the clock customer support

- Convenient online submission

- Thorough peer review

- Inclusion in PubMed and all major indexing services

- Maximum visibility for your research

Submit your manuscript at www.biomedcentral.com/submit
Biomed Central 